\title{
PERFIL DA MOBILIDADE DE ALUNOS COM DEFICIÊNCIA FÍSICA INCLUÍDOS EM REDE MUNICIPAL DE ENSINO REGULAR E AVALIAÇÃO DA ACESSIBILIDADE ESCOLAR. \\ Pôster
}

Autores deste trabalho:

Tereza Cristina Carbonari de Faria: Universidade Federal de Alfenas UNIFAL MG

Sílvia Caroline Massini Rosa: Universidade Federal de Alfenas UNIFAL-MG

Ligia de Sousa Marino: Universidade Federal de Alfenas UNIFAL-MG

Larissa de Melo Taveira: Universidade Federal de Alfenas UNIFAL- MG

Jéssica Beatriz de Matos: Universidade Federal de Alfenas UNIFAL- MG

Área do Trabalho: Fisioterapia

Data da submissão: 09/08/2018 às 16:47

\section{Justificativa}

Diante da necessidade de ampliar o conhecimento a respeito da temática e de conhecer outras experiências relacionadas às crianças com deficiências é que surgiu a motivação para desenvolver este estudo. Sair do contexto da clínica onde o ambiente é "padronizado" para neutralizar o impacto variável dos diferentes ambientes sobre a capacidade do indivíduo e avaliar o desempenho das crianças num ambiente como a escola, um ambiente habitual que apresenta o envolvimento do indivíduo numa situação de vida, seria primordial para entender de fato a funcionalidade dessas crianças e também as barreiras encontradas por elas.

\section{Objetivo(s)}

Traçar o perfil da mobilidade de alunos com deficiência física incluídos em escolas municipais de ensino regular em uma cidade no sul de Minas Gerais e avaliar a acessibilidade escolar.

\section{Método(s)}

Trata-se de um estudo transversal, no qual a avaliação da mobilidade foi realizada frente qualificação de nove domínios da Classificação Internacional de Funcionalidade, Incapacidade e Saúde (CIF) e a avaliação da acessibilidade escolar foi baseada em 36 itens das normas da ABNT NBR:9050.

\section{Resultado(s)}

Foram avaliados 13 alunos ( $n=13)$, no qual houve prevalência do sexo masculino $69,2 \%$ e idade média de 7,3 anos. Verificou-se que 53,8\% dos alunos estão no Ensino Fundamental I e 92,3\% contam com auxílio de um professor de apoio. Os diagnósticos mais frequentes foram Paralisia Cerebral $(n=4)$ e Distrofia Muscular de Duchenne $(n=3)$. Os alunos apresentaram maior dificuldade (grave a completa) nas tarefas: mover objetos com membros inferiores $(69,2 \%)$, andar $(69,2 \%)$, deslocar-se $(61,5 \%)$ e deslocar-se por diferentes locais (53,9\%). Relacionado à acessibilidade escolar todas as instituições que recebem alunos com deficiência física $(n=9)$ apresentaram barreiras. 


\section{Conclusão(ões)}

O estudo apontou maior comprometimento da mobilidade relacionada à locomoção e que existem barreiras arquitetônicas e materiais que comprometem a independência dos alunos com deficiência física e dificultam a participação ativa nos diferentes contextos escolares. 